\title{
Converting the temperature dependent Pitzer parameter of THEREDA for TOUGHREACT
}

Holger SEHER*, TORBEN Weyand, Guido Bracke, Helge C. MoOG

GRS gGmbH, Schwertnergasse 1, 50667 Cologne, Germany (*correspondance: holger.seher@grs.de)

The ongoing site selection process for a repository for high level nuclear waste in Germany is investigating salt, clay and granite rocks as possible host rocks. The pore waters of these rocks can contain saline solutions with high ionic strength.

Thermodynamic equilibria in high saline solutions can be calculated using the Pitzer approach [1]. The THEREDA project [2] provides ready-to-use parameter files for some widely used geochemical codes (PHREEQC, Geochemist's Workbench, ChemApp, and EQ 3/6). The project is going to extend this service to even more codes, one of them being TOUGHREACT.

TOUGHREACT will integrate the Pitzer approach. Scripts have been developed to convert datasets from THEREDA into parameter files for TOUGHREACT. To validate data conversion we performed benchmark calculations, comparing results with PHREEQC and TOUGHREACT. First results will be shown and discussed.

[1] K. S. Pitzer (1991): Activity Coefficients in Electrolyte Solutions (2nd ed.). CRC Press, ISBN 08493-5415-3.

[2] H. C. Moog et al. (2015): Appl. Geochem. (55) 72-84. http://dx.doi.org/10.1016/j.apgeochem.2014.12.016 